\title{
STRATEGY
}

http://www.smallbusinessinstitute.biz

\section{Entrepreneurial cognition of the business model construct: A mixed methods study of STEM and non-STEM entrepreneurs}

\author{
Gabi A. Kaffka1, Raja Singaram², Aard J. Groen ${ }^{3}$, Jeroen Kraaijenbrink ${ }^{4}$ \\ ${ }^{1}$ University Medical Center Utrecht, Universiteitsweg 98, 3508 GA Utrecht, The Netherlands. gabikaffka@hotmail.com \\ ${ }^{2}$ University of New Mexico, USA \& LM Thapar SOM, India. ilayaraja@gmail.com \\ ${ }^{3}$ University of Groningen, 9712 CP Groningen, The Netherlands, a.j.groen@rug.nl \\ ${ }^{4}$ University of Amsterdam, 1012 WX Amsterdam, The Netherlands, jk@kraaijenbrink.com \\ www.jsbs.org
}

Keywords:

Entrepreneurial cognition, Socially situated cognition, Business model, Opportunity development, Abductive analysis

\section{A B S T R A C T}

\begin{abstract}
Applying the theory of socially situated cognition, we study how entrepreneurs cognitively process the business model construct during the early stages of launching technology-based new ventures. Through an abductive reasoning procedure, we aggregate four underlying socially situated cognitive functions of the business model and describe how these functions facilitate opportunity development. We examine if the entrepreneur's educational background (STEM vs non-STEM) influences their cognitive processing of the construct. We discuss the contribution of our study to the literature on managerial cognition, business models, and to practice in detail.
\end{abstract}

\section{Introduction}

Managerial cognition literature within strategy features numerous studies that examine the cognitive influences of CEOs and top management teams on the strategy process in established firms (for reviews see Bromiley \& Rau, 2016; Narayanan et al., 2011). Similarly, entrepreneurial cognition of the entrepreneurs - knowledge structures that include the cognitive scripts, schemas and processes related to new venture decision-making - plays an important role in strategy generation and execution of new ventures (Payne et al., 2005; Maron et al., 2019). Design of the initial business model (BM) is crucial to the strategy formulation of new ventures and it is certainly subject to the influence of the entrepreneurs' cognitive processes (Morris et al., 2006; Zott \& Amit, 2007). BM design and innovation led by entrepreneurs contribute significantly to the overall firm innovation which remains the bedrock for the survival and growth of these firms (Dunne et al., 2016; Ahluwalia et al., 2017; Barwinski et al., 2020). Hence, recent studies on the role of managerial cognition on BM design have called

Journal of Small Business Strategy

2021, Vol. 31, No. 03, 148-163

ISSN: 1081-8510 (Print) 2380-1751 (Online)

(C) Copyright 2021 Small Business Institute ${ }^{\circledR}$ for more research attention into this subject (Foss \& Saebi, 2017; Frankenberger \& Sauer, 2019).

According to the theoretical perspective of socially situated cognition, entrepreneurial opportunities are cocreated through the shared cognition distributed among entrepreneurs and their stakeholders (Mitchell et al., 2011; Dew, Grichnik, Mayer-Haug, Read \& Brinckmann, 2015). Scholars have argued that the BM aids opportunity co-creation by acting as "the cognitive link between entrepreneurial appraisal of the opportunity and its exploitation" (George \& Bock, 2011, p. 88). Similarly, Doz and Kosonen (2010, p. 371) suggest that a new venture's BM functions as the "cognitive structure" that provides "a theory of how to set boundaries to the firm, how to create value, and how to organize its internal structure and governance." Taking a cognitive approach, Martins et al. (2015) showed that entrepreneurs could innovate the BMs of their firm through analogical reasoning and conceptual combinations. Building on this, we argue that entrepreneurial cognition could enable entrepreneurs to leverage the cognitive functions of the BM while designing the value creation elements of the construct as real attributes of their new venture (Massa et al., 2017). Despite the breadth of extant research on BMs

APA Citation Information: Kaffka, G. A., Singaram, R., Groen, A. J., \& Kraaijenbrink, J. (2021). Entrepreneurial cognition of the business model construct and the influence of founders' education. Journal of Small Business Strategy, 31(3), 148-163. 
(see Wirtz et al., 2016; Foss \& Saebi, 2017), the influence of entrepreneurial cognition on BM design is relatively understudied (Zott \& Amit, 2007; Massa et al., 2017). The main purpose of our study is to unpack how entrepreneurs cognitively process the $\mathrm{BM}$ construct during opportunity development.

Prior studies show that human capital characteristics affect the way entrepreneurs develop a business opportunity (Davidsson \& Honig, 2003; Brinckmann \& Kim, 2015; Digan et al., 2017). Even beyond the founding stage, human capital remains closely related to organizational innovation and performance (McDowell et al., 2018). Specifically, human capital acquired through formal education positively affects the cognitive development of entrepreneurs by aiding opportunity recognition (Shepherd \& Patzelt, 2018). Amit and Zott (2015) underscore that the professional background and education of the entrepreneurs could affect their decisions on BM design. Entrepreneurs with a background in the academic disciplines of science, technology, engineering and mathematics (the so-called STEM disciplines) tend to focus on the technical aspects of their business idea (Berry, 1996). The technical orientation of STEM-trained entrepreneurs could shift their focus away from understanding what customers value which in turn could pose a management or survival challenges for the novel business venture (West \& Noel, 2009; Schindehutte et al., 2008). Thus, results from prior studies indicate that we can expect entrepreneurs trained in STEM disciplines to cognitively process BMs differently than those from other educational backgrounds. In sum, we have two research questions that can be summarized as:

How do entrepreneurs cognitively process the business model construct during the early stages of creating a new venture?

\section{How does entrepreneurs' educational back- ground affect their cognitive processing of the business models?}

We employed a mixed methods approach to answer these questions. Using the abductive reasoning method (Mantere \& Ketokivi 2013; Wright, 2017), we compared theoretical concepts on cognitive processing of BMs with empirical findings from interviews with 56 entrepreneurs (c.f., Adam et al., 2018). Through this exercise, we identify and describe the four socially situated cognitive functions of the BM during opportunity development namely, comprehension, communication, development and analysis. To answer the second research question, we performed quantitative analysis to uncover the differences in cognitive pro- cessing of the BM among entrepreneurs based on their educational background. We find that entrepreneurs with STEM educational backgrounds draw from all the four cognitive functions while the entrepreneurs with non-STEM education predominantly use comprehension and development.

We make several contributions to theory and practice from our study. First, we add to the research on managerial cognition by providing empirical support for situated cognition shared between the entrepreneurs and their stakeholders and show how it influences the strategy process (Mitchell et al., 2011; Dew et al., 2015). Second, by focusing on the opportunity development phase of new venture creation (Shepherd et al., in press), we contribute to a series of studies that treat "business models as a facilitative intermediary in the opportunity-creation process" (George \& Bock, 2011, p. 88). We describe how this facilitation is realized through the entrepreneurs' use of socially situated cognitive functions of the BM. Third, by comparing the cognitive processing of the BM by STEM and non-STEM educated entrepreneurs, we inform the literature as to how differences in the education of the entrepreneurs plays a role during BM design (Amit \& Zott, 2015). Finally, we discuss the implications of our findings for BM design, pedagogy, and practice (Snihur et al., 2020).

\section{Theoretical Background}

\section{Entrepreneurial Cognition and Business Model Design}

The development of new business opportunities is governed by entrepreneurial cognition of the entrepreneurs. Entrepreneurial cognition is defined as, "the knowledge structures that people use to make assessments, judgments or decisions involving opportunity evaluation, venture creation and growth" (Mitchell et al., 2002, p. 97). These knowledge structures are used for 'connecting the dots' to arrive at recognition of patterns in the market. Entrepreneurs gain critical insights towards opportunity appraisal through this pattern recognition (Baron \& Ensley, 2006). Prior studies have argued that opportunity recognition and sensemaking by the entrepreneurs impacts BM design and innovation of new ventures (Spieth et al., 2014; George \& Bock, 2011). By extension, entrepreneurial cognition which drives opportunity recognition and development affects BM design in a fundamental way.

A venture's BM can be defined as the "design or architecture of the value creation, delivery, and capture mechanisms" (Teece, 2010 p. 172). A critical review of the research on BMs by Massa et al., (2017) reveals that scholars and practitioners interpret the construct in three distinct ways namely, 1) BMs as real firm attributes, 2) BMs as 
cognitive/linguistic schema and, 3) BMs as formal conceptual representations of how a business functions. It is important to note that these three views are not mutually exclusive and more than one of these interpretations often co-exist in the same study. Researchers that view the business models as cognitive schema are "concerned with how BMs are interpreted by organizational members, and their role and manifestation in social (inter)action, including organization-level sensemaking, environmental scanning and sensing opportunities and the cognitive antecedents of BM design and innovation" (Massa et al., 2017, p. 82). This approach is most germane to study how shared cognition between entrepreneurs and their stakeholders help them design their initial BM for a new venture.

Scholars that have adapted the BM as cognitive schema perspective argue that an "owner-manager's cognition and sensemaking provides the most important input into the initial business model design." (Sosna et al., 2010, p. 387). Several studies from this literature stream show that entrepreneurs could tap into both the material as well as the cognitive aspects of the BM construct at the same time (Tikkanen et al., 2005; Baden-Fuller \& Mangematin, 2013). The shared cognitive processes of executive teams have been found to impact the BM transformation in major firms (Aspara et al., 2013). BM design and change over time are closely related to the attention shifts and attention intensity of TMTs (Frankenberger \& Sauer, 2019). The search behavior, thinking style and decision-making of the entrepreneurs affect BM innovation in young ventures (Snihur \& Zott, 2020). We extend this literature by focusing on the opportunity development phase of new ventures to study the cognitive processes used by the entrepreneurs while designing BMs.

\section{Opportunity Development and Socially Situated Cogni- tion}

Mere identification of an entrepreneurial opportunity is not sufficient to realize it. Entrepreneurs must develop the opportunity by working with other stakeholders (Dimov, 2007; George \& Bock, 2011; Shepherd et al., in press). During the opportunity development phase entrepreneurs work closely with launch customers, early investors, mentors, incubators whose contribution is crucial beyond just the individual cognitive abilities of the core founders. Successful initial BM design, therefore, is a product of entrepreneurs securing commitments from these stakeholders who provide the resources required to realize the business opportunity (c.f. Sirmon et al., 2011).

Within entrepreneurial cognition literature, one of the theoretical perspectives that supports opportunity co-cre- ation is that of socially situated cognition. According to this perspective, cognition is action-oriented, embodied, situated, and distributed among multiple individuals (Smith \& Semin, 2004). Invoking this perspective to new venture creation, Mitchell et al. (2011) suggest that entrepreneurial cognition can be better understood by examining the cognitive abilities of the entrepreneurs in relation to the social situations and their stakeholders. When viewed through the lens of socially situated cognition, the activity of BM design during the opportunity development phase could be argued as an exercise of achieving shared cognition among stakeholders. In this scenario, entrepreneurs not only design the actual architecture for value creation the literal purpose of the $\mathrm{BM}$ in line with the notion of BM as a real firm attribute (Massa et al., 2017). More than that, they also use the BM to achieve shared understanding of how the entrepreneurial opportunity would be co-created and exploited with their stakeholders. We illustrate this through the socially situated cognitive functions of the BM.

\section{Educational Background and Business Model Design}

Entrepreneurial cognition is influenced by the entrepreneur's prior knowledge (Grégoire et al., 2010), such as education, work, and entrepreneurial experience (Smith, 1967; Davidsson \& Honig, 2003; Haynie et al., 2009). Given the strong influence of one's prior knowledge structures on the perception and interpretation of information (Baron \& Ensley, 2006; Grégoire et al., 2010), the formal educational background of an entrepreneur can be expected to affect how they cognitively process the BM. This is supported by Amit and Zott (2015), who assert that the educational background of the entrepreneurs would indeed affect BM design and innovation. Studies have shown that entrepreneurs with a background in the STEM disciplines tend to focus on the technical aspects of their business idea. For example, Berry (1996) describes how firms which are dominated by technologists in the management are likely to be technology-driven instead of being market-driven. This could have serious effects on the survival and growth of small technology-based firms. Similarly, researchers studying technology-based ventures observe that "A common concern with entrepreneurs [...] is that they often lack commercial experience, resulting in a tendency to focus only on the technical aspects of innovation." (Knockaert et al., 2011, p. 790). Other studies have shown that technology entrepreneurs often tend to hire others with the same technology educational background leading to the lack of commercial experience among the venture's team members (Ensley \& Hmieleski, 2005; Franklin et al., 2001). The ensuing predominantly 'technical mindset' can impede the en- 
trepreneur's focus on value for the customer, which in turn causes a survival challenge for the novel business venture (West \& Noel, 2009; Schindehutte et al., 2008). These findings point to the influence of education of the entrepreneurs on $\mathrm{BM}$ design that warrants further research investigation. In sum, the focus of our study is to examine how the BM is cognitively processed by entrepreneurs to achieve shared cognition among stakeholders, and to show how this is affected by the educational background of entrepreneurs.

\section{Method}

To accomplish our research goal, we used an abductive reasoning procedure (Mantere \& Ketokivi 2013; Wright, 2017). "Abductive analysis is a qualitative data analysis approach aimed at generating creative and novel theoretical insights through a dialectic of cultivated theoretical sensitivity and methodological heuristics" (Timmermans \& Tavory, 2012, p. 180). The overview of methodological steps shown in Figure 1 provides the outline for our abductive approach of iterative triangulation of findings by recursive comparison of theory and empirical data. Timmermans and Tavory (2012, p. 180) prescribe further that "researchers should enter the field with the deepest and broadest theoretical base possible and develop their theoretical repertoires throughout the research process." We first describe the deductive steps by which we established the socially situated cognitive functions a BM from extant theory. Then, we show how we inductively validated those functions with the empirical analysis of our interview data.

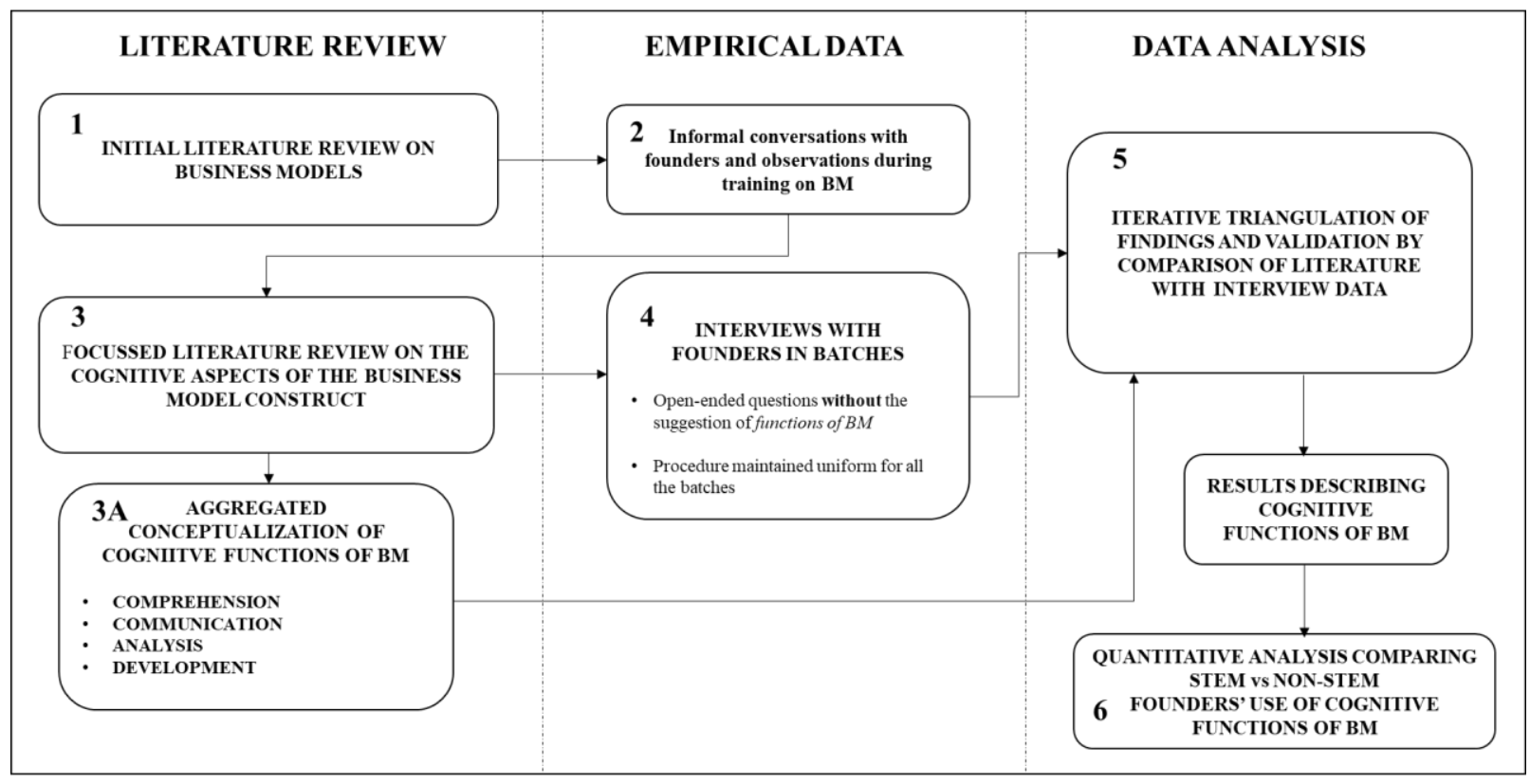

Figure 1. Overview of Method

\section{Theoretical Grounding}

In order to ground our arguments in extant literature on BMs, we performed a focused literature review through which we gathered support for how BMs could serve as cognitive links during opportunity development. As an initial starting point, we used two special issues on the topic of BMs from well-known academic journals in strategy and entrepreneurship, namely, Strategic Entrepreneurship Journal and Long Range Planning. From the papers comprised in those two special issues, we identified studies which investigated the instrumental roles, functions or purposes for which entrepreneurs use the BM in support of intended value creation. Next, we carried out a bibliography analysis on BM functions using the papers cited in the references section of the initial set of articles which resulted in the expansion of the literature covered in a snowballing fashion. The results of this literature review are presented in Table 1, which shows the repetitive cognitive themes we aggregated from current literature on BMs. These aggregated cognitive functions of the BM during new venture creation were labelled as comprehension, communication, analysis and development. Empirical validation and further elaboration of these themes is obtained through abductive reasoning incorporating both theory and interview data from the entrepreneurs in tandem. We describe them in the results section. 


\section{Empirical Setting}

To validate the cognitive functions derived from theory and to explain how they manifest in practice, we conducted interviews with entrepreneurs involved in opportunity development activities for at least the past one year. The setting was a business incubation program affiliated with a large technological university in the Netherlands. The one-year incubation program provided institutional support for entrepreneurs developing novel technology-based ventures in the form of office facilities, trainings, one-on-one coaching, and expert panel feedback on business progress. The program also facilitated the entrepreneurs to network with industry players as well as the investment community that consisted of corporate and private venture capital firms located in the Netherlands and USA. The program offered multiple classes taught by experts from USA and Europe including one on BM design. Hands-on training enabled participants to design their venture's value creation logic, and the entrepreneurs had worked on this task for at least a year before we formally interviewed them.

\section{Interviews}

We had informal conversations with the participants of the training class to understand how they perceived and used the BM for their venture. Formal in-depth interviews were scheduled when the entrepreneurs exited the incubation program in batches. Every quarter about a dozen entrepreneurs completed the program and the interviews took place over a period of two years. We conducted structured, open-ended interviews to capture the entrepreneur's reports about their meanings, impressions, and cognitive processing of the BM. The entrepreneurs also spoke about their experience with the incubation program, who they collaborated with, mentorship received, and results achieved. By prior agreement, firm performance metrics were kept confidential between the entrepreneurs and the management of the incubator. Therefore, we did not have access to that data. To keep the researcher bias low, we did not specifically use the functions aggregated from literature or related terms that might prime the entrepreneurs. All the interviews were audio-taped and transcribed to satisfy the criterion of low-inference descriptors which ensure high data validity (Silverman, 2001).

\section{Educational Background}

In addition to the qualitative data, we collected basic data about the respondents: their age, gender, and education. Education is coded in terms of two dimensions: the level of education [primary school to graduate education] and the type of education of respondents [STEM vs NON-STEM]. The basis of our STEM classification was informed by two sources. First, for a comprehensive coding of professional fields, we drew on the International Standard Classification used by the United Nations Educational, Scientific and Cultural Organization (UNESCO). Second, drawing on Berry's (1996) descriptions of technical disciplines, we further distinguished the professional fields of study. Based on this, those disciplines with educational content relating to natural sciences, technology, engineering and mathematics are coded as 'STEM' disciplines. All other educational disciplines, such as social sciences, liberal arts, and humanities, are coded as 'non-STEM' disciplines.

\section{Sample Characteristics}

Sixty-five entrepreneurs that participated in the program were interviewed, but we had to exclude 9 entrepreneurs who had either quit the opportunity development activities or were not pursuing a new venture but were trying to grow their existing business. Our final sample containsed 56 interviewees of which eight are female entrepreneurs. Due to the dropouts, we had a balanced sample with 28 STEM educated and 28 non-STEM educated entrepreneurs and this balance was unintentional. The average age of entrepreneurs in this sample is 45 years $(S D=10$ years). They had 14 years of work experience on the average before making the decision to become an entrepreneur ( $S D=10$ years). The entrepreneurs on average had 7 years of previous entrepreneurial experience ( $S D=7$ years). 19 participants in this sample were serial or portfolio entrepreneurs. Overall, the average educational level of entrepreneurs in our sample is high. More than half of the sample had a graduate degree, and 32 entrepreneurs had obtained a doctorate degree. 19 entrepreneurs in the STEM group had doctorate degrees in the field of natural science or technology. The Netherlands as a country is known for a high educational level (OECD, 2019), which is reflected in this sample. The high level of education is also likely due to the research setting. The incubation program was affiliated to a technical university which typically attracts graduate and post-graduate alumni who wish to pursue the commercialization of their scientific research results.

\section{Data Coding and Interrater Reliability}

We carried out discourse analysis of the interviews. Discourse analysis is an interpretive process in which key categories, recurrent themes and terms help to organize the data (Tonkiss, 1998; Silverman, 2001). Accordingly, 
Table 1

Focused literature review and aggregated cognitive functions of the business model construct

\begin{tabular}{|c|c|c|c|}
\hline Source & Type of study & Use of the venture's business model in the study & $\begin{array}{l}\text { Aggregated Cognitive } \\
\text { Functions of BM from } \\
\text { Current Literature }\end{array}$ \\
\hline $\begin{array}{l}\text { Osterwalder et al. } \\
(2005)\end{array}$ & $\begin{array}{l}\text { Meta } \\
\text { Literature } \\
\text { Review }\end{array}$ & $\begin{array}{l}\text { Understanding, sharing, analyzing, managing, pros- } \\
\text { pecting and patenting of a value creation logic }\end{array}$ & $\begin{array}{l}\text { Comprehension, } \\
\text { Communication, } \\
\text { Analysis, Development }\end{array}$ \\
\hline $\begin{array}{l}\text { Doganova \& } \\
\text { Eyquem-Renault } \\
(2009)\end{array}$ & $\begin{array}{l}\text { Empirical Case } \\
\text { Study }\end{array}$ & $\begin{array}{l}\text { Function of providing a 'bounding' base for articula- } \\
\text { ting and defining the logic of value creation, secon- } \\
\text { dly the function of communicating about it to others, } \\
\text { and thirdly the function of objectifying and singulari- } \\
\text { zing (calculating) the logic of value creation }\end{array}$ & $\begin{array}{l}\text { Comprehension, } \\
\text { Communication, Analysis }\end{array}$ \\
\hline $\begin{array}{l}\text { Baden-Fuller \& } \\
\text { Morgan (2010) }\end{array}$ & $\begin{array}{l}\text { Meta } \\
\text { Literature } \\
\text { Review }\end{array}$ & $\begin{array}{l}\text { Experimentation, innovation, refinement and varia- } \\
\text { tion of one's business opportunity }\end{array}$ & Analysis, Development \\
\hline $\begin{array}{l}\text { Demil \& Lecocq } \\
(2010)\end{array}$ & $\begin{array}{l}\text { Empirical Case } \\
\text { Study }\end{array}$ & $\begin{array}{l}\text { Creation of internal coherence between the various } \\
\text { components of the firm's business model; facilitation } \\
\text { of change and innovation of specific components or } \\
\text { the whole business model }\end{array}$ & $\begin{array}{l}\text { Comprehension, Analysis, } \\
\text { Development }\end{array}$ \\
\hline $\begin{array}{l}\text { Nenonen \& Stor- } \\
\text { backa }(2010)\end{array}$ & $\begin{array}{l}\text { Literature } \\
\text { Review And } \\
\text { Empirical } \\
\text { Interactive } \\
\text { Study }\end{array}$ & $\begin{array}{l}\text { Co-creation of value by offering a means (a model) } \\
\text { which facilitates collaboration between network } \\
\text { partners }\end{array}$ & $\begin{array}{l}\text { Communication, } \\
\text { Development }\end{array}$ \\
\hline $\begin{array}{l}\text { Mason \& Spring } \\
(2011)\end{array}$ & $\begin{array}{l}\text { Empirical Case } \\
\text { Study }\end{array}$ & $\begin{array}{l}\text { A business model describes agency (activities) in } \\
\text { value creation and network structure such as key } \\
\text { partners in value creation }\end{array}$ & Comprehension \\
\hline $\begin{array}{l}\text { Spieth et al. } \\
(2014)\end{array}$ & $\begin{array}{l}\text { Meta } \\
\text { Literature } \\
\text { Review }\end{array}$ & $\begin{array}{l}\text { A business model has three major roles: Explaining } \\
\text { the business, running the business and developing } \\
\text { the business }\end{array}$ & $\begin{array}{l}\text { Comprehension, } \\
\text { Development }\end{array}$ \\
\hline $\begin{array}{l}\text { Martins et } \\
\text { al.(2015) }\end{array}$ & $\begin{array}{l}\text { Meta } \\
\text { Literature } \\
\text { Review }\end{array}$ & Innovation of value creation logic & Development \\
\hline
\end{tabular}

we coded the entrepreneurs' reports based on the cognitive functions of comprehension, communication, analysis, and development by identifying signal words from theory. A codebook developed through this process ensured the validity, reliability and thus transparency of the analysis. The unit of analysis is an individual sentence as well as a logical chain of sentences in the transcripts of the interviews. To ensure the objectivity and validity of our qualitative data analysis we used multiple coders and checked for inter-rater reliability (Flick, 2007) following best practices laid out by previous qualitative studies in entrepreneurship (Grégoire et al., 2010). Two coders independently read the initial set of interviews from the entrepreneurs and coded for how they described, reasoned, and explained the use of the BM. The initial coding was compared among the coders and coding assignments were checked. Any discrepancies were discussed and resolved. We repeated this procedure in multiple rounds of qualitative coding. Cohen's kappa yielded an inter-rater reliability of $84 \%$, which is considered excellent (Landis \& Koch, 1977; Fleiss, 1981; Brennan \& Prediger,1981). After the compilation of the cognitive functions of the BM, we counted how many of these functions were 
mentioned by each entrepreneur. This served as the basis for quantitative comparisons between entrepreneurs grouped by education.

\section{Results}

We were specifically interested in unpacking the cognitive aspects of the BM construct that entrepreneurs tap into during opportunity co-creation (Massa et al., 2017). In line with George and Bock (2011), we find that the BM acts as a cognitive intermediary that helps entrepreneurs through comprehension, communication, analysis, and development of their value creation logic. It is important to note that these cognitive functions are socially situated in that they facilitate the interaction between the entrepreneurs and their stakeholders and the establishment of shared cognition among them. Our findings are summarized in Table 2 in which we have compiled of detailed descriptions of how the functions aid entrepreneurs in their cognitive processing of the BMs. In this section, we explain these functions in detail.

\section{Comprehension}

A broad understanding of all the moving parts of the business is an important aspect that guides the thinking of entrepreneurs designing the initial BM for their startup. In addition to the understanding of the parts, the interrelationships between them must be well understood. We aggregate quotes which signified that the entrepreneurs used the BM to gain an all-encompassing, big picture view of the firm's proposed value creation logic. Such understanding, descriptions and visualizations are grouped under the cognitive function of comprehension. Signal words such as "overview," "comprehensive," "total picture," "total concept" etc., from the entrepreneurs' quotes exemplify this. The following quotes illustrate the cognitive function of comprehension:

R05: Yes, nice, a new way of looking at it... [...] I thought it to be quite - it is rather nice because it actually gives an impression of the total concept on one page, yes, that model does that well."

"R17: The business model can be used for a better way of thinking about all the aspects that have to do with the product, customers, service, and suppliers - altogether. If you're very busy you are inclined to think very fragmented: there is an issue and you search for a solution."
R08: "Yes, [the business model] I found very enlightening because it gives a total picture. And it not only forces you but gives you the opportunity to formulate and form that total picture. So that there are no more inconsistencies in it."

We did find that the comments on comprehension were influenced by the business model canvas tool (Osterwalder \& Pigneur, 2010), which was used in the training class and is adopted popularly in practice (c.f., Sohl et al., 2020). Entrepreneurs' answers reveal how they use the cognitive function of comprehension to achieve clarity about the value creation logic of their venture and how they iron out the inconsistencies in the BM design. We observed that the interactions with stakeholders triggered the entrepreneurs' reflection of the BM components and their interrelationships, which in turn enhanced comprehension.

\section{Communication}

Communicating with the stakeholders is an important activity for the entrepreneurs during the BM design phase of a startup. It enables them to mobilize support and orchestrate the required resources. Facilitation of communication is an important cognitive function of the BM construct that we were able to validate from our analyses. Quotes from entrepreneurs clearly mentioned the communicative aspects via signal words such as, "get the message across," "getting everyone on the same page," "brainstorming with everyone," etc. The entrepreneurs converse with stakeholders both within (e.g. managers, engineers) and outside the venture (e.g., partners, customers, investors). Clear communication aids the achievement of common understanding among multiple parties and focuses the attention of the individuals towards what work needs to get done. Relevant quotes include:

R14: "We use [the business model] to get everyone on the same page within the organization, I have presented it to the organization, that is good, then everybody knows what we are doing. And then it's also input for our action plans."

R28: "I know now I can create, show my business model to a new audience and get the message across in 15 minutes, I can do that now whenever I need to, that is a good feeling." 


\section{Analysis}

Entrepreneurs engaged in designing the initial BM must evaluate the pros and cons of the value creation logic being constructed. Before deciding on a specific configuration of the building blocks of the BM, they must gauge the viability of various alternatives. This process may at times involve generating multiple potential BMs and assessing the fit of each BM for their venture. The cognitive function of analysis helps the entrepreneurs use the BM construct as a tool to experiment on these possibilities and compare the available options against each other. Analysis also helps them to identify the measures that they need to track over time. Critical reflection through analysis helps entrepreneurs make course corrections when required. The following quotes illustrate the cognitive function of analysis:

R02: "I designed about six business models [...]. Before starting the venture, I picked the most practical business models to start with. And it ended [...] with a list of criteria of which business models can yield the most profit for me."

R25: "From what I learned most and what I look at every month, is the business model. That gives me a very good image of where we stand and where we go and if we're on the right track."

\section{Development}

$\mathrm{BM}$ design is a dynamic process subject to change and improvisation as the entrepreneurs gather more information and recruit various stakeholders to work with them. The cognitive function of development demonstrates how entrepreneurs use the BM to institute continuous improvement of various aspects of their new venture. In certain cases, owing to the complexity of the value proposition and value capture, not one but a portfolio of BMs must be designed. Entrepreneurs use the cognitive function of development to improve the existing BM components, to react appropriately to the changes in the competitive landscape, and to create a BM portfolio. Following quotes illustrate how entrepreneurs have used the BM to document change and innovate their value creation logic over time.

R28: "Now we have the business model to step by step focus on execution [..], to document changes in the business model."

R24: "It requires continuous attention, a living document, you can put your successive experi- ences in it."

R57: "In first instance, my business model was directed towards product development. [...] I think that actually, in particular with the situation after the bankruptcy, we have examined everything again. Before we were very product-focused, afterwards we had a better balance between product-focus and market-focus, and strongly oriented towards a good cost and revenue structure. That is quite facilitated by the business model."

Additional quotes on the cognitive functions are provided in Table 1. Overall, we deciphered that the attention of the entrepreneurs is directed and refined when they employ the four socially situated cognitive functions the BM. They also reported that the BM enabled them to structure their thinking on the intended value creation while sidestepping distractions. One of them observed:

R17: And because you are often dominated by everyday issues that means that when you are thinking about where you want to go with the venture you often think very opportunistically. With the [...] business model you learn to think about this structurally.

The socially situated nature of entrepreneurial cognition was exemplified by the entrepreneurs' reports on how they engaged multiple stakeholders such as customers, partners, investors, managers, and engineers as sources of information and knowledge during opportunity development. The nature of our research setting, a university-affiliated incubator, also helped the entrepreneurs seek input from an array of other parties outside their firm such as coaches, professors, experts, as well as their peers in the incubation program. The BM construct was quite useful in helping the entrepreneurs gather purposeful feedback by tapping into the cognition distributed across these stakeholders.

Quantitative analysis of the interview data yielded further insights. The effect of educational background (STEM vs non-STEM) on the use of the cognitive functions by the entrepreneurs is displayed in Figure 2. Figure 3 shows the number of functions reported per entrepreneur in each of these groups. All the entrepreneurs, regardless of education type or education level, utilized the comprehension and development cognitive functions of the BM. STEM educated entrepreneurs used the communication and analytical cognitive functions more frequently than non-STEM educated entrepreneurs. Technological 
Table 2

Cognitive processing of the business model construct by entrepreneurs leading new ventures

\begin{tabular}{cl}
$\begin{array}{c}\text { Cognitive } \\
\text { Function of the BM }\end{array}$ & \multicolumn{1}{c}{ Empirical Evidence - Quotes from Entrepreneurs } \\
\hline & $\begin{array}{l}\text { R08. "It is a perfectly fine model, everything is in it, everything which is relevant, yes. That } \\
\text { means it is comprehensive instead of you running the risk of getting caught up in details. } \\
\text { By visualizing a business model you realize you're in a process and that still you must keep } \\
\text { your eyes on other points as well." }\end{array}$
\end{tabular}

Comprehension

\section{Communication}

Analysis
R02. "You see [the business model] as a system: how do you create something and how do you sell something? Yes, that overview... Overview of the business, it's logic."

R12. "The $[B M]$, in which all aspects of marketing of the products are brought up and can be worked out... business model is, sort of, real strong."

R04. "In fact, the business model offers a very easy way to communicate with all partners."

R06. "And in addition, [the BM] is good because you are becoming aware yourself about those things, but you also learn, because you have to explain it to others, how you have to build a presentation, because you have different business models for different types. For investors a different story than for customers. The business model helps because you have ordered your business aspects well."

R16. "I use [the business model construct] in order to validate ideas, to see if the idea I have, if it is practically applicable, and if it can be offered on a commercial base."

R27. "So if you look closely you see that it were actually ten business model. [...], and we focused on two business models; one focused on consultancy, and the one on software, and now we'll see how to we can go on with that."

R36. "Now [...] we will try to make a better distinction between different business model, and work on them."
Entrepreneurs cognitively process the Business Model construct by:

Understanding, describing and visualizing the venture's business model design or parts of it

Thinking about specific aspects of the venture's value creation logic, to understand and/or gain insight into it

Capturing the interrelationships among various components of the business

Reflection with the aim of comprehension

Communication about the venture's value creation logic with third parties, inside or outside the venture

Engagement of/or interaction with other parties such as managers and engineers in the process of creating or reflecting on the value creation logic

Identification of measures to improve management, track issues of the firm's value creation logic over time

Comparison of various alternative value creation logics, also with that of competitors to test it (in terms of prototyping, simulation or business cases)

Experimentation with or testing of different value creation logics and to reflect what you can do with that logic in the future ('what would work better')

Reflection with the aim of critical examination or assessment of the venture's business model 
R24. "So we have examined, by means of the business model, how we can bring it together, [my] ideas like I have explained [...] and then in that way make the other part possible because of that."

R56. "The best was, what I learned the most from [...] is the business model. [...] Small

Development changes are very easy to implement in it so that you can see with one glance if you will reach your goals."

R46. "Yes, by means of the business model - I don't know if you know it -, I have changed a number of things, mainly that I make more advertisement... so actually in support of the cold acquisition, yes, that sort of thing... [BM] is very useful for that."
Planning, changing, refining or implementing activities regarding the venture's business model, for example in order to detail, adapt or improve the existing business model

Reacting to changing competitive landscape, alignment of the BM with strategy and the firm's technology

Innovation of the existing business model

Creating a business model portfolio 
complexity of the business idea and the number of stakeholders involved could increase the need for communication while also necessitating analysis. At the same time, we must infer the causal relationship between education type and cognitive functions of the BM with caution given that all the ventures are technology-based. More research on these variables is warranted. To ascertain if the entrepreneurs from the STEM and non-STEM education groups invoke the cognitive functions of the BM construct differently, we performed a t-test. From Levene's $F$-test we

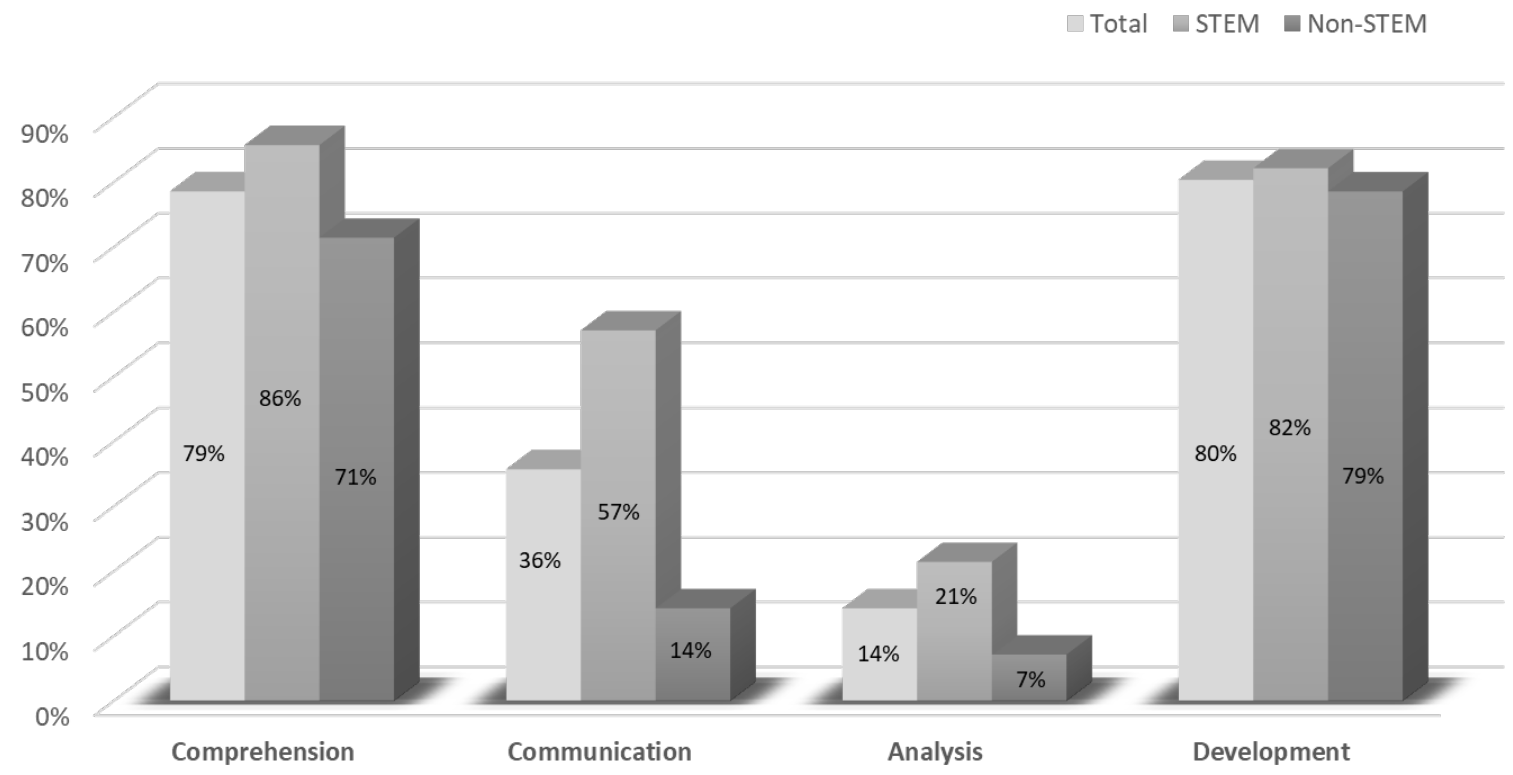

Figure 2. Cognitive Functions of the BM reported by Entrepreneurs' Education Type

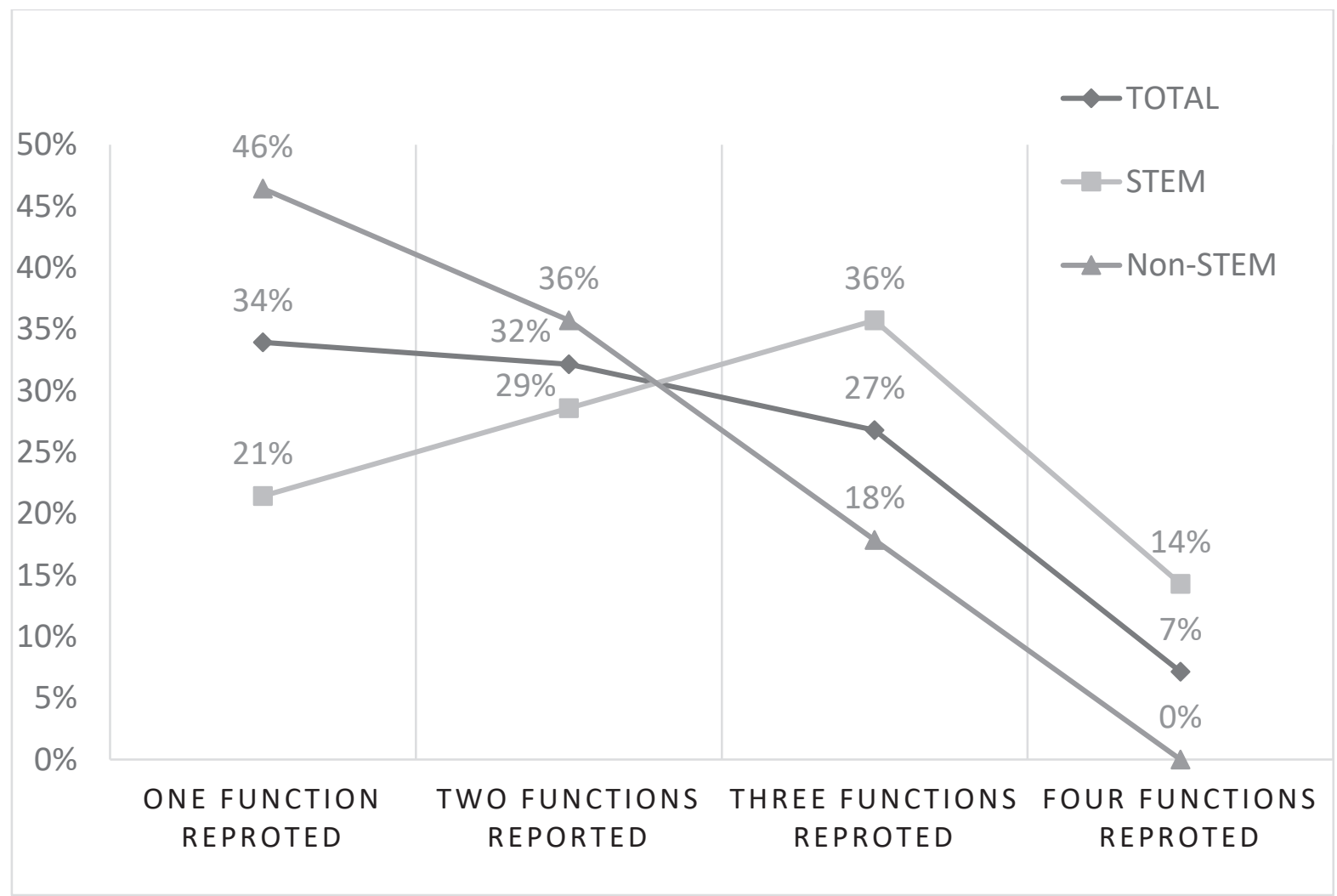

Figure 3. Number of Cognitive Functions of BM reported by Entrepreneurs' Education Type 
checked for the homogeneity of variances between the samples based on education. The results of the F-test show that the sub-samples do not differ significantly regarding their variance; $F(27)=1.71, p=0.09$, F value $<$ F Critical value. We followed this with running t-test assuming equal variances between the entrepreneurs with different educational backgrounds. Based on the results, we could confirm that the number of cognitive functions of the BM reported was significantly different between entrepreneurs with STEM education $(M=2.43, S D=0.96)$ and non-STEM educated entrepreneurs $(M=1.71, S D=0.76), \mathrm{t}(54)=3.01, p=$ 0.004. Comparison of the use of cognitive functions of the BM based on educational level both within and across the education types did not yield any meaningful differences.

\section{Discussion}

We started our research inquiry with the question of how entrepreneurs performing opportunity development activities cognitively process the BM in concert with stakeholder interactions. Using the theoretical lens of socially situated cognition and interviews from entrepreneurs, we were able to extract and validate four cognitive functions of the BM which we explicated in detail. In this section, we discuss the theoretical and practical implications of our findings.

\section{Theoretical Implications}

Studies dealing with the influence of managerial cognition on strategy processes have emphasized the role played by executive cognition in designing and shaping the BM of large firms (Sosna et al., 2010; Aspara et al., 2013). The attention patterns and attention intensity of top management teams (TMTs) are known to drive changes and BM innovation (Frankenberger \& Sauer, 2019). We extend the literature on the cognitive perspective of strategy through our study of the cognitive processes that entrepreneurs employ during BM design (Snihur \& Zott, 2020). Here, we find evidence that the BM helps entrepreneurs refine their attention and efforts during opportunity development. Our findings also suggest that the BMs channel the reflective attention of the entrepreneurs towards finding performance metrics, experimenting with alternatives in design and the assessment of the current BM design. Through the BM's cognitive function of development, entrepreneurs focus their attention on change and innovation in response to the competitive landscape and refine product-market fit. From this, we argue that while the attention of the entrepreneurs may affect $\mathrm{BM}$ design initially, once the BM becomes concrete it in turn directs the attention of the entrepreneurs towards next steps thus unfolding a virtuous attention cycle. These findings are in line with Massa et al. (2017), who describe that BMs can function as cognitive schema that can operate as a 'focusing device' to aid decision-making.

Previous studies have proposed that the BM functions as a 'cognitive link' between opportunity identification and exploitation (Doz \& Kosonen, 2010; George \& Bock, 2011). We explicate the nature and content of this cognitive link through the four socially situated cognitive functions and provide empirical proof for these arguments. We add to the stream of literature which views the BM as a facilitative intermediary during opportunity co-creation (George \& Bock, 2011). This facilitation is validated through the quotes from the entrepreneurs who report that they use the BM to get the stakeholders on board using comprehension and communication. As proposed by Mitchell and colleagues, we find that by enhancing comprehension and communication, entrepreneurs actively work at communicative, relational and group levels of situated entrepreneurial cognition (Mitchell et al., 2011). Both communication and comprehension could be closely associated with sensemaking, sensegiving, sensedemanding and sensebreaking processes that the entrepreneurs and their stakeholders engage in while dealing with uncertainty during the early stages of a venture (Hill \& Levenhagen, 1995; Spieth et al., 2014; Kaffka \& Krueger, 2018; Kaffka et al., 2021). Entrepreneurs, as a result, are able to orchestrate the resources required for the new venture thereby advancing opportunity co-creation (Sirmon et al., 2011; Frankenberger \& Stam, 2020). The socially situated cognition perspective that explains the shared cognition between entrepreneurs and critical stakeholders is complementary to the shared mental models approach pursued by other scholars that study entrepreneurial vision in teams in later stages of a venture (see Hensel \& Visser, 2019). Our study provides strong empirical proof for entrepreneurial cognition being distributed across multiple social agents (Dew et al., 2015; Kaffka et al., 2021). Researchers from the entrepreneurship as design perspective (Berglund et al., 2020) view BMs as abstract artifacts constructed by entrepreneurs in order to instantiate entrepreneurial opportunities (Berglund \& Glaser, 2021). We inform this literature by showing how such an artifact is designed through shared narratives, between entrepreneurs and their stakeholders, that leverage the cognitive functions of the BM. Furthermore, these scholars regard narrative entrepreneurial artifacts as "sensemaking devices that are not defined by their materiality, but rather by their ability to relate individuals, objects, and events in meaningful accounts" (Berglund \& Glaser, 2021). From our empirical observations, we find that the BM artifact can also function as one such sensemaking device that helps entrepreneurs clarify the business oppor- 
tunity through comprehension, communication, analysis, and development. Therefore, we suggest that some abstract artifacts like the BM could also have narrative properties especially during its design in the opportunity development phase. Future research investigations may help us resolve if entrepreneurial artifacts should be kept categorically distinct or if a single artifact can simultaneously take on multiple properties that are abstract, narrative or material in nature (Berglund \& Glaser, 2021). Finally, Amit and Zott (2015) had proposed that the educational background of the entrepreneur may affect BM design. We test this empirically to find that STEM and non-STEM educated entrepreneurs do differ in their cognitive processing of the BM lending support to their argument and highlighting the need for more research in this direction to understand and make sense of these differences.

\section{Practical Implications}

In practice, entrepreneurs at the helm of new ventures and small businesses, consultants, incubators, and educators would benefit immensely from leveraging various cognitive functions of the BM identified and validated in our study. The socially situated cognition perspective adopted in our study extends the focus beyond the entrepreneurs to also include their interaction with those that help them exploit the entrepreneurial opportunity. Entrepreneurs find themselves typically cognitively overloaded, having to make numerous decisions in the customer development phase of a startup (York \& Danes, 2014). The function of comprehension serves a dual purpose of converging their attention while also conserving the entrepreneurs' time and efforts. It also helps them bring internal and external stakeholders on the same page, leading to avoidance of errors and misconceptions. Similarly, entrepreneurs could use the BM to tailor-make their communication to cater to the expectations of their valued audience, whether it is a customer or a supplier. The communication function allows for framing and reframing of the core aspects of the business for the purpose of clarification and gaining support. Reflection of the entrepreneurs facilitated by input from stakeholders such as investors, customers, mentors etc., allow them to experiment with alternatives, discover performance metrics and enhance product-market fit. Practitioners could use the functions of analysis and development for achieving BM innovation. Lastly, the need for better frameworks to educate engineers and non-entrepreneurs on the entrepreneurial process, including the design of BMs, has been emphasized by researchers (e.g., Mahto \& McDowell, 2018; Snihur, Lamine \& Wright, 2020). Teaching the cognitive functions of the BM along with the value creation and capture as- pects of the construct would enhance its utility for students as well as practitioners.

\section{Limitations and Future Directions}

Our study's limitations stem from the context in which the interviews were conducted which is a technology-incubator. Here, all the entrepreneurs were pursuing a technology-based new venture irrespective of their educational background even though the complexity of technology being commercialized had differences. Future studies that investigate the differences between entrepreneurs (STEM versus non-STEM) could match the nature of the venture in addition to education type. Furthermore, there was low variance in the level of education of the entrepreneurs in our sample. Close affiliation with the technical university that led the incubator was one of the reasons for this. Researchers interested in understanding the role of educational level (Sonfield \& Lussier, 2014) on BM design would be better served in pursuing samples with larger variance on this construct. Similarly, the low sample size of entrepreneurs also limited our ability to perform robust quantitative analyses of the differences between the entrepreneurs. In addition, education is just one of the sources of human capital which has other attributes such as experience and training that future studies could explore in relation with the initial BM design. The entry threshold at the incubator was set in such a way that entrepreneurs with promising ideas and domain experience were chosen to be part of the oneyear support program. This meant that the participants had substantial entrepreneurial experience before they started their current venture. As a result, we were not able to observe the differences between novice and experienced entrepreneurs and how they might be different in processing the BMs during their initial design. The interviews took place at the end of the startup incubation program. In order to trace the development of the initial BM design more interviews or observation points could be planned by researchers to get a better idea of dynamics BM design (Cosenz \& Noto, 2018) at early stage startups (Snihur \& Zott, 2020) and the cognitive processes associated with it. Finally, the scope of our research did not include the type of BMs designed (e.g., freemium versus subscription) or performance of the venture owing to their nascency. Thus, future research studies could investigate the various intersections of BM type, performance, and entrepreneurial cognition. Beyond overcoming said limitations, studies connecting BM design to the cognition and sensemaking of the top management teams, their stakeholders and resultant resource orchestration for small businesses would be fruitful pursuits from both theory and practice perspectives. 


\section{Conclusion}

The core functions of a BM are to specify a venture's logic for value creation, capture and delivery (Osterwalder, Pigneur \& Tucci, 2005). Beyond these core functions, the BM also offers socially situated cognitive functions that entrepreneurs leverage to orchestrate support for exploiting entrepreneurial opportunities. Intentional use of comprehension, communication, analysis, and development functions of the BM would be immensely useful in achieving shared cognition among stakeholders thereby propelling nascent ventures to next stages of growth.

\section{References}

Adam, M., Strähle, J., \& Freise, M. (2018). Dynamic capabilities of early-stage firms: Exploring the business of renting fashion. Journal of Small Business Strategy, 28(2), 49-67.

Ahluwalia, S., Mahto, R. V., \& Walsh, S. T. (2017). Innovation in small firms: Does family vs non-family matter? Journal of Small Business Strategy, 27(3), $39-49$

Amit, R., \& Zott, C. (2015). Crafting business architecture : The antecedents of business model design. Strategic Entrepreneurship Journal, 9(4), 331-350.

Aspara, J., Lamberg, J. A., Laukia, A., Tikkanen, H. (2013). Corporate business model transformation and inter-organizational cognition: The case of Nokia. Long Range Planning, 46(6), 459-474.

Baden-Fuller, C., \& Mangematin, V. (2013). Business models: A challenging agenda. Strategic Organization, 11(4), 418-427.

Baden-Fuller, C., \& Morgan, M. S. (2010). Business models as models. Long Range Planning, 43(2), 156-171.

Baron, R. A., \& Ensley, M. D. (2006). Opportunity recognition as the detection of meaningful patterns: Evidence from comparisons of novice and experienced entrepreneurs. Management Science, 52(9), 13311344.

Barwinski, R., Qiu, Y., Aslam, M. M., \& Clauss, T. (2020). Changing with time: New ventures' quest for innovation. Journal of Small Business Strategy, 30(1), 18-30.

Berglund, H., Bousfiha, M., \& Mansoori, Y. (2020). Opportunities as artifacts and entrepreneurship as design. Academy of Management Review, 45(4), 825-846.

Berglund, H., \& Glaser, V. (2021). The Artifacts of Entrepreneurial Practice. In N. Thompson, O. Byrne, B. Teague, \& A. Jenkins (Eds.). Edgar Elgar.

Berry, M. M. (1996). Technical entrepreneurship, strategic awareness and corporate transformation in small high-tech firms. Technovation, 16(9), 487-522.

Brennan, R. L., \& Prediger, D. J. (1981). Coefficient kappa: Some uses, misuses, and alternatives. Educational and Psychological Measurement, 41(3), 687-699.

Brinckmann, J., \& Kim, S. M. (2015). Why we plan: The impact of nascent entrepreneurs' cognitive characteristics and human capital on business planning. Strategic Entrepreneurship Journal, 9(2), 153-166.

Bromiley, P., \& Rau, D. (2016). Social, behavioral, and cognitive influences on upper echelons during strategy process: A literature review. Journal of Management, 42(1), 174-202. https://doi. org $/ 10.1177 / 0149206315617240$

Cosenz, F., \& Noto, G. (2018). A dynamic business modelling approach to design and experiment new business venture strategies. Long Range Planning, 51(1), 127-140.

Davidsson, P., \& Honig B. (2003). The role of social and human capital among nascent entrepreneurs. Journal of Business Venturing, 18(3), 301-331.

Demil, B., \& Lecocq, X. (2010). Business model evolution: In search of dynamic consistency. Long Range Planning, 43(2), 227-246.

Dew, N., Grichnik, D., Mayer-Haug, K., Read, S., \& Brinckmann, J. (2015). Situated entrepreneurial cognition. International Journal of Management Reviews, 17(2), 143-164. https://doi.org/10.1111/ijmr.1205

Digan, P. S., Kerrick, S. A., Cumberland, D. M., \& Garrett, R. P. (2017). Role of knowledge and organizational form on opportunity evaluation. Journal of Small Business Strategy, 27(2), 65-89.

Dimov, D. (2007). Beyond the single-person, single-insight attribution in understanding entrepreneurial opportunities. Entrepreneurship Theory and Practice, 31(5), 713-731.

Doganova, L., \& Eyquem-Renault, M. (2009). What do business models do? Innovation devices in technology entrepreneurship. Research Policy, 38(10), 1559-1570.

Doz, Y. L., \& Kosonen, M. (2010). Embedding strategic agility: A leadership agenda for accelerating business model renewal. Long Range Planning, 43(2-3), 370-382.

Dunne, T. C., Aaron, R. J., McDowell, W. C., Urban, D. J., \& Geho, P. R. (2016). The impact of leadership on small business innovativeness. Journal of Business Research, 69(11), 4876-4881.

Ensley, M. D., \& Hmieleski, K. M. (2005). A comparative study of new venture top management team composition, dynamics and performance between universi- 
ty-based and independent start-ups. Research Policy, 34(7), 1091-1105.

Fleiss, J. L. (1981). Statistical methods for rates and proportions (2nd ed.). John Wiley.

Flick, U. (2007). Managing quality in qualitative research. Sage.

Frankenberger, K., \& Sauer, R. (2019). Cognitive antecedents of business models: Exploring the link between attention and business model design over time. Long Range Planning, 52(3), 283-304.

Frankenberger, K., \& Stam, W. (2020). Entrepreneurial copycats: A resource orchestration perspective on the link between extra-industry business model imitation and new venture growth. Long Range Planning, 53(4), 101872. https://doi.org/10.1016/j. 1rp.2019.02.005

Franklin, S. J., Wright, M., \& Lockett, A. (2001). Academic and surrogate entrepreneurs in university spinout companies. The Journal of Technology Transfer, 26(1-2), 127-141.

Foss, N. J., Saebi, T., (2017). Fifteen years of research on business model innovation: How far have we come, and where should we go? Journal of Management 43(1), 1-28.

George, G., \& Bock, A. J. (2011). The business model in practice and its implications for entrepreneurship research. Entrepreneurship Theory and Practice, 35(1), 83-111.

Grégoire, D. A., Barr, P. S., \& Shepherd, D. A. (2010). Cognitive processes of opportunity recognition: The role of structural alignment. Organization Science, 21(2), 413-431.

Haynie, J. M., Shepherd, D. A., \& McMullen, J. S. (2009). An opportunity for me? The role of resources in opportunity evaluation decisions. Journal of Management Studies, 46(3), 337-361.

Hensel, R., \& Visser, R. (2019). Explaining effective team vision development in small, entrepreneurial teams: A shared mental models approach. Journal of Small Business Strategy, 29(1), 1-15.

Hill, R. C., \& Levenhagen, M. (1995). Metaphors and mental models: Sensemaking and sensegiving in innovative and entrepreneurial activities. Journal of Management, 21(6), 1057-1074.

Kaffka, G., \& Krueger, N. (2018). The entrepreneurial 'mindset': Entrepreneurial intentions from the entrepreneurial event to neuroentrepreneurship. In G. Javadian, V. Gupta, D. Dutta, G. Guo, A. Osorio, \& B. Ozkazanc-Pan (Eds.), Foundational research in entrepreneurship studies (pp.203-224). Palgrave Macmillan. https://doi.org/10.1007/978-3-319-
73528-3_10

Kaffka, G. A., Singaram, R., Groen, A. J., \& Kraaijenbrink, J. (2021). "Yes and..., but wait..., heck no!": A socially situated cognitive approach towards understanding how startup entrepreneurs process critical feedback. Journal of Small Business Management. DOI: 10.1080/00472778.2020.1866186

Knockaert, M., Ucbasaran, D., Wright, M., \& Clarysse, B. (2011). The relationship between knowledge transfer, top management team composition, and performance: The case of science-based entrepreneurial firms. Entrepreneurship: Theory and Practice, 35(4), 777-803.

Landis, J. R., \& Koch, G. G. (1977). The measurement of observer agreement for categorical data. Biometrics, 33(1), 159-174.

Mahto, R. V., \& McDowell, W. C. (2018). Entrepreneurial motivation: A non-entrepreneur's journey to become an entrepreneur. International Entrepreneurship and Management Journal, 14(3), 513-526.

Mantere, S., \& Ketokivi, M. (2013). Reasoning in organization science. Academy of Management Review. 38(1), 70-89.

Martins, L. L., Rindova, V. P., \& Greenbaum, B. E. (2015). Unlocking the hidden value of concepts: A cognitive approach to business model innovation. Strategic Entrepreneurship Journal, 9(1), 99-117.

Maron, S., Lussier, R. N., Sonfield, M. (2019). Entrepreneurial strategy: The relationship between firm size and levels of innovation and risk in small businesses. Journal of Small Business Strategy, 29(3), 33-45.

Mason, K., \& Spring, M. (2011). The sites and practices of business models. Industrial Marketing Management, 40(6), 1032-1041.

Massa, L., Tucci, C. L., \& Afuah, A. (2017). A critical assessment of business model research. Academy of Management Annals, 11(1), 73-104.

McDowell, W. C., Peake, W. O., Coder, L., \& Harris, M. L. (2018). Building small firm performance through intellectual capital development: Exploring innovation as the "black box". Journal of Business Research, $88,321-327$.

Mitchell, R. K., Busenitz, L. W., Lant, T., McDougall, P. P., Morse, E. A. (2002). Toward a theory of entrepreneurial cognition: Rethinking the people side of entrepreneurship research. Entrepreneurship Theory and Practice, 27(2), 93-104.

Mitchell, R. K., Randolph-Seng, B., \& Mitchell, J. R. (2011). Socially situated cognition: Imagining new opportunities for entrepreneurship research. Academy of Management Review, 36(4), 774-776. 
Morris, M., Schindehutte, M., Richardson, J., \& Allen, J. (2006). Is the business model a useful concept? Conceptual, theoretical, and empirical insights. Journal of Small Business Strategy, 17(1), 27-50.

Narayanan, V. K., Zane, L. J., \& Kemmerer, B. (2011). The cognitive perspective in strategy: An integrative review. Journal of Management, 37(1), 305-351.

Nenonen, S., \& Storbacka, K. (2010). Business model design: Conceptualizing networked value co-creation. International Journal of Quality and Service Sciences, 2(1), 43-59.

Organisation for Economic Cooperation and Development, (OECD). (2019). Education at a glance 2019: OECD indicators. OECD Publishing.

Osterwalder, A., \& Pigneur, Y. (2010). Business model generation: A handbook for visionaries, game changers, and challengers. Wiley Inc.

Osterwalder, A., Pigneur, Y., \& Tucci, C. L. (2005). Clarifying business models: Origins, present, and future of the concept. Communications of the Association for Information Systems, 16(1), 1-25.

Payne, G. T., Kennedy, K. H., Blair, J. D., Fottler, M. D. (2005). Strategic cognitive maps of small business leaders. Journal of Small Business Strategy, 16(1), 27-40.

Schindehutte, M., Morris, M. H., \& Kocak, A. (2008). Understanding market-driving behavior: The role of entrepreneurship. Journal of Small Business Management, 46(1), 4-26.

Shepherd, D. A., \& Patzelt, H. (2018). Prior knowledge and entrepreneurial cognition. In D. A. Shepherd \& H. Patzelt (Eds.), Entrepreneurial cognition (pp. 7-49). Palgrave Macmillan.

Shepherd, D. A., Sattari, R., \& Patzelt, H. (in press). A social model of opportunity development: Building and engaging communities of inquiry. Journal of Business Venturing. https://doi.org/10.1016/j. jbusvent.2020.106033

Silverman, D. (2001). Interpreting qualitative data: Methods for analyzing talk, text, and interaction. Sage Publications.

Sirmon, D.G., Hitt, M.A., Ireland, R.D., \& Gilbert, B.A. (2011). Resource orchestration to create competitive advantage. Journal of Management, 37(5), 13901412.

Smith, E. R., \& Semin, G. R. (2004). Socially situated cognition: Cognition in its social context. Advances in Experimental Social Psychology, 36, 53-117.

Smith, N. R. (1967). The entrepreneur and his firm: The relationship between type of man and type of company. Occasional Papers, Bureau of Business and Economic Research, Michigan State University, 109.
Snihur, Y., Lamine, W., \& Wright, M. (2020). Educating engineers to develop new business models: Exploiting entrepreneurial opportunities in technology-based firms. Technology Forecasting and Social Change 164. https://doi.org/10.1016/j.techfore.2018.11.011

Snihur, Y., \& Zott, C. (2020). The genesis and metamorphosis of novelty imprints: How business model innovation emerges in young ventures. Academy of Management Journal, 63(2), 554-583.

Sohl, T., Vroom, G., \& Fitza, M. A. (2020). How much does business model matter for firm performance? A variance decomposition analysis. Academy of Management Discoveries, 6(1), 61-80.

Sonfield, M., \& Lussier, R. N., (2014). The influence of the entrepreneur's education level on strategic decision making. Journal of Small Business Strategy, 24(1), 19-28.

Sosna, M., Trevinyo-Rodríguez, R. N., \& Velamuri, S. R. (2010). Business model innovation through trial-and-error learning: The Naturhouse case. Long Range Planning, 43(2), 383-407.

Spieth, P., Schneckenberg, D., \& Ricart, J. E. (2014). Business model innovation-state of the art and future challenges for the field. $R \& D$ Management, 44(3), 237-247.

Teece, D. J. (2010). Business models, business strategy and innovation. Long Range Planning, 43(2-3), 172-194.

Tikkanen, H., Lamberg, J. A., Parvinen, P., \& Kallunki, J. P. (2005). Managerial cognition, action and the business model of the firm. Management Decision, 43(6), 789-809.

Timmermans, S., \& Tavory, I. (2012). Theory construction in qualitative research from grounded theory to abductive analysis. Sociological Theory, 30(3), 167186.

Tonkiss, F. (1998). Continuity/change. In C. Jenks (Ed.), Core sociological dichotomies.(pp. 34-48). Sage.

West, G. P., \& Noel, T. W. (2009). The impact of knowledge resources on new venture performance. Journal of Small Business Management, 47(1), 1-22.

Wirtz, B. W., Pistoia, A., Ullrich, S., \& Gottel, V. (2016). Business models: Origin, development, and future research. Long Range Planning, 49(1), 36-54.

Wright, P. (2017). Making great theories. Journal of Management Studies, 54(3), 384-390.

York, J. L., \& Danes, J. E. (2014). Customer development, innovation, and decision-making biases in the lean startup. Journal of Small Business Strategy, 24(2), 21-39.

Zott, C., \& Amit, R. (2007). Business model design and the performance of entrepreneurial firms. Organization Science, 18(2), 181-199. 